\title{
POLA PASTORAL GEREJA KEUSKUPAN AGUNG ENDE (KAE) PADA MASA PANDEMI COVID 19
}

Oleh: Frederikus Dhedhu

\begin{abstract}
Abstrak
Sejak Konsili Vatikan II Gereja memiliki pandangan yang sangat positif terhadap dunia. Dunia dengan segala harapan dan kecemasannya merupakan tempat dimana Gereja hidup. Gereja dipanggil untuk tetap setia pada misinya yakni menampakkan wajah belas kasih Allah. Ketika dunia dilanda oleh Covid 19, Gereja dipanggil untuk membaca tanda-tanda zaman, menafsirkannya dalam terang sabda Allah dan menyakinkan umat beriman bahwa dalam situasi sulit sekalipun tetap ada peluang untuk menata dan menghidupkan karya pastoralnya secara lebih baik, lebih kreatif dan lebih bertanggung jawab agar tetap menjawabi kebutuhan umat. Dengan cara demikian, Gereja tetap menjadi tanda dan sarana keselamatan; tanda dan sarana yang menegaskan bahwa tidak ada kekuatan lain yang dapat memisahkan manusia dari cinta Alah .
\end{abstract}

Kata-kata kunci : Covid 19, sakit/penyakit, belas kasih, iman, karya pastoral.

\section{Pengantar}

$\mathrm{K}$

onsili Vatikan II berhasil mengatasi pemisahan antara dunia dan Gereja. Dunia tidak lagi dilihat secara negatif, sebagai sumber dosa, tetapi dilihat secara positif yakni bagai panggung sejarah manusia; tempat manusia hidup. Dunia dilihat sebagai "locus theologicus" dan partner dari Gereja. Tanpa dunia tidak ada Gereja. Karena itu Gereja dan dunia menghasilkan sejarah bersama, berjalan bersama menuju kesempurnaan Kerajaan Allah. Sejarah manusia dengan segala harapannya dan kecemasannya (Covid 19) adalah medan dimana kerajaan Allah dibangun. Jemaat kristiani tidak bisa menarik diri dan menutup diri dalam kemapanan Gereja demi privatisme tetapi dipangil untuk terlibat dalam sejarah umat manusia. ${ }^{1}$

Karena itu dokumen Konsili Vatikan II, Gaudium et Spes menegaskan:

Untuk melaksanakan tugas seperti itu, Gereja selalu wajib menyelidiki tanda-tanda zaman dan menafsirkannya dalam cahaya Injil. Demikianlah Gereja dengan cara yang sesuai dengan setiap angkatan akan dapat menanggapi pertanyaanpertanyaan, yang pada segala zaman diajukan oleh orang-orang tentang makna hidup sekarang dan di masa mendatang, serta tentang hubungan timbal balik antara keduanya. Maka perlulah dikenal dan dipahami dunia kediaman kita beserta harapan-harapan, aspirasi-aspirasi, dan sifat-sifatnya yang sering dramatis" (GS. No. 4).

Pandemi Covid 19 sebagai sebuah realitas yang mencemaskan dan menakutkan dunia perlu disikapi oleh Gereja dalam terang sabda Allah. Memang disadari bahwa sabda Allah tidak secara langsung membalikkan kenyataan dari situasi negatif ke situasi positif sesuai harapan manusia tetapi ada kepastian bahwa sabda Tuhan memberikan visi, orientasi ke mana semestinya kaum beriman harus melangkah dan sekaligus melahirkan tindakan konkrit yang harus dilakukan untuk mengatasi bahaya pandemi Covid 19.

\footnotetext{
${ }^{1}$ Aurora Sarcia, Parrocchia si nasce Comunita si diventa, (Edizione Chiesa-mondo, 2004), hlm. 38.
} 


\section{Pandangan Gereja Tentang Penyakit (Covid 19)}

\subsection{Landasan Utama}

\subsubsection{Landasan Biblis ${ }^{2}$}

Pandangan Gereja tentang penyakit (Covid 19) bersumber pada Kitab Suci. Kitab Suci Perjanjian Lama berbicara tentang Yahweh dengan beberapa kualitas ilahi berikut ini:

a. Yahweh adalah Bapa yang mencintai dan memperhatikan Israel.

Dalam Kitab Suci baik Perjanjian Lama (PL) maupun Perjanjian Baru (PB), kata yang paling penting adalah kata perjanjian. Kata "perjanjian” diulang sebanyak 189 kali. Allah berjanji untuk menyelamatkan umat Israel, sebab Israel adalah anak kandung-Nya. Dialah Bapa yang menciptakan dan melahirkan Israel (Bil. 32:6 Yes. 64:8, Kel. 4:22, Bil. 14:1 Hos. 11:1)

b. Yahweh adalah gembala yang memperhatikan dan memberikan kehidupan.

Dalam kitab Yehezkiel, Yahweh menjanjikan suatu masa depan yang aman bagi umat pilihan-Nya (Yeh. 34:25). Untuk melukiskan gambaran Yahweh sebagai gembala yang memperhatikan dan memberikan kehidupan kepada Israel, ditegaskan kembali perjanjian Sinai tentang hubungan antara Yahweh dan Israel (Yeh. 34 :30-31, Yes. 40:10-11).

c. Yahweh adalah tabib yang menyembuhkan.

Penegasan utama yang ditemukan dalam Kitab Suci PL berhubungan dengan hal ini terdapat dalam Kitab Keluaran 15:26." Akulah Tuhan yang menyembuhkan engkau". Suatu pernyataan yang singkat, jelas, esensiil, yang menunjukkan bagaimana Allah sendiri menyatakan diriNya kepada Israel bahwa Dia adalah Pribadi yang menyembuhkan. Selain pribadi yang menyembuhkan Yahweh juga pribadi yang memberikan kehidupan kepada Israel (1 Sam. 2:6, Kel. 20:3, Bil. 5:7, 32:39).

\subsubsection{Landasan Kristologis ${ }^{3}$}

Landasan Kristologis dari sikap Gereja terhadap Pandemi Covid 19 dapat ditemukan dalam tiga (3) hal ini:

a. Yesus Menunjukkan Tiga Wajah Allah yakni Allah sebagai Bapa (Mat. 6:26.32, 7:11, 23:9, 7:7-11, 6: 25-34, Luk. 11:13, 15:11-32. Gambaran Allah sebagai Bapa melukiskan kasih dan kesetiaan Bapa yang tak terbatas kepada Israel. Dosa dan kesalahan Israel tidak pernah akan membatalkan kasih Bapa. Allah sebagai Gembala. Yesus menyebut dirinya sebagai gembala justru karena Dia adalah pribadi yang menampilkan Allah sebagai gembala. (Luk. 15:4-7, Yoh. 10:15-18, Mat. 26:31. Allah sebagai Tabib. Penyakit fisik membuat manusia tak berdaya, tidak dapat mengalami keselamatan yang utuh, karena itu dalam karya pewartaan-Nya Yesus juga menyembuhkan orang-orang yang menderita berbagai macam penyakit (Mrk. 2:17, Mat. 9:12-13, Luk. 5:31).

${ }^{2}$ Leonardo Nunzio Di Taranto, Fare Pastorale Della Salute In Italia, (Oggi, Edizioni CVS 2010), hlm. 48-59.

${ }^{3}$ Ibid, 60-68. 


\section{b. Yesus Adalah Tabib Fisik Dan Kejiwaan}

Perhatian dan bantuan bagi yang sakit dan menderita merupakan bagian dari misi dan perutusan Gereja. Gereja seperti Yesus sendiri selalu mau ada bersama mereka yang menderita. Yesus mendoakan dan menyembuhkan orang sakit, memberikan penghiburan dan pengharapan. Dengan cara seperti itu Yesus mau menegaskan bahwa sakit dan penyakit sesungguhnya bukanlah kutukan Tuhan. Komunitas perdana dan penginjil Lukas memahami dengan baik hubungan khusus yang dihidupi oleh Yesus dengan realitas penyakit dan penderitaan (Kis 10:37-38).

\section{c. Pengukuhan mesianis Yesus sebagai wujud konkrit keselamatan Allah "saat ini"}

Keselamatan Allah bukanlah sesuatu yang abstrak tetapi sesuatu yang konkrit sebab dialami oleh mereka yang menderita berbagai macam penyakit: penyakit fisik dan penyakit psikis. Dalam seluruh keempat Injil terdapat 19 peristiwa penyembuhan yang dilakukan oleh Yesus. Para penulis Injil menilai bahwa intervensi Yesus menyembuhkan orang-orang sakit merupakan realisasi program mesianis yang disampaikan-Nya di Sinagoga sebagai awal dari pewartaaan Kerajaan Allah (Luk. 4:16-21).

\subsubsection{Landasan Eklesiologis ${ }^{4}$}

Sepanjang perjalanan historisnya, Gereja telah menunjukkan kesetiaannya pada ajaran Kristus dan para rasul untuk memastikan kehadiran-Nya yang bermakna dalam dunia dengan rupa-rupa penderitaan. Melalui berbagai institusi yang bergerak dalam bidang kesehatan, Gereja terlibat dalam memperjuangkan kelayakan hidup bagi orangorang kecil dan orang-orang sakit.

a. Konsili Nicea tahun 325, mewajibkan semua kota keuskupan membangun tempat perawatan khusus bagi para perantau yang sakit dan orang-orang miskin. Berdasarkan himbauan konsili tersebut maka di setiap keuskupan didirikan cukup banyak tempat-tempat tersebut.

b. St. Basilius, Uskup Kaisare di Kappadokia (330-379) membangun sebuah rumah sakit yang cukup besar pada pintu gerbang kota. St. Gregorius Nazianz menyebutnya sebagai "tempat bantuan belaskasih" dimana semua penyakit disembuhkan dengan sentuhan jiwa yang tenang bagi semua orang tanpa membeda-bedakannya.

c. St. Yohanes Krisostomus, uskup Konstantinopel (346-407): mengajak umatnya untuk menyiapkan sebuah kamar khusus di rumah masing-masing bagi orang-orang sakit yang sedang dalam perjalanan.

Selanjutnya seluruh karya pastoral Gereja untuk membantu orang-orang sakit dan orang-orang miskin sangat berkembang dengan semangat pembaharuan Gereja yang terjadi pada Konsili Vatikan II.

\subsection{Landasan Praktis (Perwujudan Iman) ${ }^{5}$}

Motivasi untuk hidup sehat tidak hanya sebatas upaya manusiawi untuk mencapai hidup sehat tetapi merupakan ekspresi iman. Pada titik ini dimensi perilaku menjadi

\footnotetext{
${ }^{4}$ Ibid, 68-70

${ }^{5}$ Proyek Kelangsungan Hidup Anak melalui LSM Agama, Program Kerjasama Antara Pemerintah RI Dan UNICEF, Pedoman Hidup Sehat Menurut Agama Katolik, (Jakarta:UNICEF, 1992), hlm. 3-5.
} 
penting untuk diperhatikan berhubungan dengan semua upaya pencapaian hidup yang sehat.

a. Manusia sebagai citra Allah.

Allah telah menciptakan manusia, langit, bumi dan segala isinya dalam keadaan baik (Kej. 1:10;13:19;25). Manusia diberi peran khusus untuk menata alam dan memanfaatkannya sesuai dengan kebutuhnnya.

b. Manusia dipanggil untuk mengembangkan diri.

Firman Allah: "Baiklah kita menjadikan manusia...., agar menguasai ikan-ikan di laut, burung-burung di udara". Kutipan ini mengandung makna yang jelas yakni upaya pengembangan diri baik bidang rohani dan jasmani dengan tujuan untuk mencapai idealisme kristiani yakni kesempurnaan.

c. Semua pihak bertanggung jawab atas perbaikan kesehatan.

Dalam amanatnya kepada para dokter pada tanggal 25 November 1957, Paus Pius XII menegaskan: "Akal budi kodrati dan moral kristiani menyatakan bahwa manusia mempunyai hak dan kewajiban mennyelenggarakan apa yang perlu untuk memelihara kesehatan".

\section{Kebijakan Pastoral Gereja Kae Dalam Masa New Normal}

Karya pastoral Gereja adalah karya Allah sendiri, sebab Allah yang berinisiatif untuk menyelamatkan manusia. Mediasi keselamatan melalui Gereja tetap memiliki sumber aslinya dalam keputusan bebas dan rencana Allah sendiri. Gambaran tersebut di satu sisi bertujuan untuk mengatasi resiko reduksi karya pastoral pada level "humanisme" dengan akibat kehilangan dimensi transenden dan di lain pihak juga bertujuan mengatasi resiko "spiritualisme", dengan akibat kehilangan dimensi manusiawi. Sebab Allah yang menyatakankan diri-Nya adalah Allah yang masuk dalam sejarah dan kehidupan konkrit manusia (LG No.2). ${ }^{6}$

Pada tataran aplikasi pastoral, karya pastoral merupakan karya yang dilaksanakan secara sadar dan bertanggung jawab dalam Gereja dan bukannya sebuah tindakan kosong tanpa makna (aktivisme), maka sebelum dan sesudah melaksanakannya, harus direfleksikan. Refleksi yang dilakukan adalah refleksi teologis sebab selalu didasarkan pada Sabda Allah sendiri. Dengan demikian praktek pastoral selalu membutuhkan teologi untuk mengarahkan tindakan pastoral, agar tidak terjebak pada pemutlakan pengalaman manusia dan hal-hal teknis saja. Sebaliknya teologi perlu membuka diri dan membiarkan diri dipertanyakan oleh praksis pastoral untuk mengembangkan satu refleksi teologis yang tidak terlepas dari kehidupan konkrit (Covid 19).

Karena itu Pandemi Covid 19 kiranya tidak menyurutkan semangat umat untuk melaksanakan kegiatan-kegiatan pastoral untuk menegaskan bahwa Allah yang diimani adalah Allah yang senantiasa mencintai umatNya. Sebab semua prinsip teologis dan kriteria praktis yang disebutkan di atas harus mengerucut pada satu sintesa akhir dalam hukum cintakasih. Hukum cintakasih bersumber pada paham teologis tentang cinta Allah sendiri. Cinta Allah tersebut memiliki satu sejarah yang panjang, berawal dari penciptaan, revelasi dan penebusan. Semuanya merupakan tindakan cinta dan keterlibatan Allah dalam sejarah manusia.

${ }^{6}$ Giovanni Villata, L'agire della Chiesa, Indicazione Di Teologia Pastorale, (Edizione Dehoniane Bologna, 2009), hlm. 98. 
Dalam masa pandemi Covid 19, Gereja KAE dipanggil untuk selalu menilai dirinya secara tetap dan kreatif, bertolak dari cara Allah bertindak dalam karya penyelamatan manusia. Para fungsionaris pastoralnya diajak untuk membiarkan diri diinspirasikan oleh pedagogi Allah, yang dengan penuh cinta menemui manusia dan memimpinnya menuju kepada keselamatan. Pedagogi Allah adalah pedagogi yang dicirikan oleh cinta Allah sendiri dalam dan melalui Yesus. Jika Gereja atau paroki menerapkan cara yang sama dalam karya pastoralnya secara khusus dalam masa new normal ini, maka umat akan mengetahui dan lebih dari itu meyakini bahwa Allah adalah cinta. Dalam konteks itu dapat dikatakan bahwa kualitas dari karya pastoral paroki sangat bergantung pada proses verifikasi kegiatan paroki yang mengacu pada prinsip cinta kasih. Sebab secara prinsipiil bukan kuantitas kegiatan pastoral yang menumbuhkan komunitas paroki menjadi sebuah persekutuan tetapi kualitas kegiatan pastoral itu sendiri yakni bobot cinta kasih. ${ }^{7}$

Karena itu walaupun dalam masa Pandemi Covid 19 dan masa New Normal ini, agen pastoral tidak bisa menerapkan irama pastoral KAE yang tetap dan sekaligus melaksanakan banyak kegiatan pastoral sebagaimana biasanya dalam komisi-komisi dan divisi-divisi tetapi kita dapat melaksanakan beberapa kegiatan utama/strategis sambil memperhatikan kebijakan Pemerintah serta protokol kesehatan. Yang penting adalah kegiatan-kegiatan pastoral yang dilaksanakan dalam masa New Normal merupakan kegiatan pastoral dengan bobot cinta kasih. Karena itu visi iman dalam kegiatan-kegiatan pastoral tetap harus dijaga agar yang "teknis" tidak mengalahkan/menghilangkan yang "teologis" atau sebaliknya, tetapi berjalan seiring dalam rangka saling melengkapi.

\section{Kegiatan Praktis Pastoral Gereja Kae Dalam Masa Pandemi Covid 19}

Bentuk kegiatan dari masing-masing bidang diharapkan menyentuh kondisi khusus yang sedang dialami oleh umat manusia seluruhnya khususnya umat KAE (Kondisi Covid 19). Masing-masing bidang pelayanan termasuk komisi-komisinya dapat menggarapnya sesuai dengan kekhasan tugas masing-masing ${ }^{8}$.

\subsection{Bidang Pewartaan}

Menghadirkan, melanjutkan, dan mewujudkan tugas perutusan Yesus Kristus adalah tugas umat beriman. Fokus utama adalah menyelamatkan umat dengan mengajarkan nilai-nilai kerajaan Allah, melalui aneka kegiatan peribadatan agar paroki menjadi persekutuan pewartaan. Nilai-nilai kerajaan Allah yang diajarkan oleh Gereja harus menjadi landasan bagi segenap kaum beriman untuk menata kehidupannya dalam masa new normal menghadapi pandemi Covid 19. Secara konkrit kebenaran, keadilan, kedamaian, dan cinta kasih menjadi modal dasar bagi kaum beriman untuk bersama-sama dengan semua orang yang berkehendak baik bersatu melawan ancaman Covid 19.

\subsection{Bidang Pembinaan}

Membawa kaum beriman kepada kekudusan yakni pola hidup yang selalu berkenan kepada Allah dan selalu berada dalam persekutuan dengan Allah agar Gereja menjadi persekutuan cintakasih. Kekudusan kaum beriman dalam berbagai kelompok-kelompok kategorial seharusnya terwujud dalam pola hidup yang melihat hidupnya sendiri dan hidup sesama sesama sebagai anugerah istimewa dari Allah sendiri. Hidup dengan nilai sedemikian besar itu patut dijaga dan dirawat dari berbagai ancaman termasuk ancaman Covid 19.

${ }^{7}$ Sergio Pintor, L'uomo via della Chiesa, Manuale Di Teologia Pastorale, (Edizione Dehoniane, 1992), hlm. 110-111.

${ }^{8}$ Pontificium Consilium Pro Laicis, Laici Oggi, La Parrocchia Ritrovata Percorsi Di Rinnovamento, (Libreria Editrice Vaticana, 2007), hlm. 177-179. 


\subsection{Bidang Kemasyarakatan}

Menyelamatkan umat melalui peran kepemimpinan dan kegembalaan agar Gereja menjadi persekutuan pelayanan. Tekanan utama ada dalam fungsi kegembalaan dan kepemimpinan untuk menghantar, membimbing, mempersatukan semua menjadi satu kawanan dengan satu gembala. Kepemimpinan dan kegembalaan yang dijalankan dalam Gereja merupakan kepemimpinan dan kegembalaan yang menampilkan ciri solidaritas dan kepedulian terhadap sesama yang menderita dan berkekurangan melalui karya-karya sosial-karitattif, terutama dalam masa-masa sulit pandemi Covid 19.

\section{Penutup}

Warta keselamatan tidak hanya diwartakan kepada mereka yang menderita tetapi juga kepada mereka yang merawat dan mendampingi para penderita. Karena itu perangkat pastoral KAE secara khusus komisi/lembaga dan divisi diharapkan dapat melaksanakan misi pembebasan umat/masyarakat melalui kegiatan-kegiatan khusus dalam masa new normal. "sesungguhnya, segala sesuatu yang kamu lakukan untuk salah seorang dari saudaraKu yang paling hina ini, kamu telah melakukannya untuk Aku” (Mat. 25:40).

\section{$\underline{\text { Daftar Kepustakaan }}$}

Leonardo, N. 2010. Fare Pastorale Della Salute In Italia. Oggi, Edizioni CVS.

Pintor, S. 1992. L’uomo via della Chiesa, Manuale Di Teologia Pastorale. Edizione Dehoniane.

Proyek Kelangsungan Hidup Anak melalui LSM Agama, Program Kerjasama Antara Pemerintah RI Dan UNICEF, 1992. Pedoman Hidup Sehat Menurut Agama Katolik. Jakarta: UNICEF.

Pontificium Consilium Pro Laicis, Laici Oggi. 2007.La Parrocchia Ritrovata Percorsi Di Rinnovamento. Libreria Editrice Vaticana.

Sarcia, A. 2004. Parrocchia si nasce Comunita si diventa, Edizione Chiesa-mondo.

Villata, G. 2009. L'agire della Chiesa, Indicazione Di Teologia Pastorale, Edizione Dehoniane Bologna. 